\title{
A subjetividade e a etnografia doméstica em Last words
}

\section{Subjectivity and domestic ethnography in Last words}

Beatriz D’Angelo Braz ${ }^{1}$

\footnotetext{
${ }^{1}$ É bacharel em Letras pela Universidade de São Paulo (USP) e em Comunicação Social, habilitação em Cinema, pela Fundação Armando Alvares Penteado (FAAP). Possui mestrado em Multimeios pelo Instituto de Artes da Universidade Estadual de Campinas (Unicamp). Atualmente, é doutoranda em Literatura pela Universidade de Brasília (UnB) e bolsista Capes.E-mail: beatrizbraz@gmail.com
} 
Resumo: este artigo propõe uma análise do documentário Last words (1998), do cineasta holandês Johan van der Keuken. Autor de mais de cinquenta documentários, Van der Keuken se destaca por sua constante experimentação cinematográfica, tanto em aspectos formais quanto temáticos. Last words, um dos últimos filmes do documentarista, exemplifica sua inserção no documentário reflexivo ao registrar os últimos momentos de sua irmã, Joke, que padece de um câncer. Este artigo centra-se, então, na representação da subjetividade e da morte no documentário, que realiza uma etnografia doméstica em que o documentarista relembra e reflete, por meio da irmã, sua própria trajetória e vivência familiar.

Palavras-chave: documentário; subjetividade; modo reflexivo; morte; etnografia.

Abstract: this article aims to analyze the documentary Last words (1998), from the Dutch filmmaker Johan van der Keuken. Author of more than 50 documentaries, Van der Keuken stands out by his constant experimentation in filmmaking, both with respect to formal aspects and to themes. Last words, one of the filmmaker's last films, is an example of his entering into the field of the reflexive documentary by recording the last moments of his sister Joke's life, who is suffering from cancer. The analysis here focusses on the film representation of subjectivity and death and how Van der Keuken makes a domestic ethnography in which he remembers and rethinks, through his sister, his own background and family life.

Keywords: documentary; subjectivity; reflexive mode; death; ethnography. 


\section{Introdução}

O documentarista holandês Johan van der Keuken produziu, ao longo de suas quatro décadas de carreira, 55 documentários até sua morte, em 2001. Entretanto, apenas a partir da década de 1990 sua obra foi redescoberta pela crítica francesa, em especial François Niney e Serge Toubiana², ambos da revista Cahiers du Cinéma, passando a ganhar maior destaque internacional. Van der Keuken, que também era fotógrafo, caracterizou-se por realizar pesquisas cinematográficas e ter forte caráter experimental em seus filmes, nos quais a montagem e a forma fílmica ocupam papel central.

A estrutura narrativa própria dos filmes de Van der Keuken levou-o, na década de 1990, a dialogar com a enunciação em primeira pessoa no documentário, trazendo para seus filmes um forte traço subjetivo e poético, sobretudo em um dos seus documentários mais célebres, De grote vakantie (Férias prolongadas, 1999), exibido em 2001 e 2005 no festival É tudo verdade, juntamente com outros trabalhos do documentarista.

Férias prolongadas sucede e mantém diálogo temático com Laatste woorden: mijn zusje Joke (Last words: my sister Yoka, 1998), filme que dá corpus a este artigo. Em ambos, além do caráter subjetivo e autobiográfico, a temática é a mesma: a morte. Ainda que em aspectos formais, sobretudo no que tange ao enquadramento, os filmes sejam muito diferentes - em Férias prolongadas, Van der Keuken utiliza o plano ponto-de-vista, em que a câmera, em boa parte das sequências, assume a posição física do documentarista, chegando a enquadrar suas pernas enquanto ele sobe uma montanha, ao passo que, em Last words, o foco recai sobre sua irmã, que é filmada objetivamente -, a subjetividade, a morte e a passagem do tempo são os elementoschave da narrativa de ambos. Se em Férias prolongadas o documentarista trata da sua morte iminente, em Last words ele registra, por meio de entrevista, os últimos momentos de sua irmã, que está em estágio terminal, acometida de câncer. O filme, então, centra-se em uma reflexão sobre a vida, a morte, a doença e as lembranças do passado, com base em um discurso subjetivo, em primeira pessoa, de Joke, a irmã

\footnotetext{
${ }^{2}$ Há dezesseis entradas ao se buscar, na Cahiers du Cinéma, o nome de Van der Keuken. Destas, apenas cinco são anteriores a 1993, quando foi publicado o texto "Being there", de Niney, na edição 465, de março de 1993. Toubiana publica uma entrevista com o documentarista no número 517, de outubro de 1997, e é o autor principal do dossiê em homenagem a Van der Keuken publicado após sua morte, intitulado "La dernière leçon de Johan Van der Keuken”, no número 554, de fevereiro de 2001. Disponível em: <https:// goo.gl/JaeeRV>. Acesso em: 26 jul. 2018.
} 
do documentarista, ao reconstituir fragmentos de memória da infância e da vida em família de ambos.

Apesar de estruturar-se em entrevistas, o filme se distancia do modelo predominante de documentário, centrado no modo expositivo. Van der Keuken faz-se presente como sujeito-da-câmera ${ }^{3}$, chegando a adquirir a espessura de personagem (RAMOS, 2008). Sua voz em off faz perguntas, comentários e pedidos a sua irmã, guiando o relato registrado pela câmera. O documentário não almeja uma reconstrução cronológica da biografia da irmã, centrada em datas ou em uma sequência lógica, mas opta por desenvolver livremente um relato pessoal e subjetivo.

As ferramentas analíticas para a contextualização e análise desse documentário situam-se no domínio dos estudos de cinema, especificamente fundamentados pelos teóricos Roger Odin, Michael Renov e David MacDougall, com recortes que aproximam o material tratado no filme à etnografia doméstica e ao discurso subjetivo no cinema.

\section{A etnografia doméstica, a subjetividade e a imagem da morte}

A tradição documentária - o centramento na questão do "real”, da "verdade" e no conceito de "mostração"4 desenvolvido por Gaudreault (1989) - é retomada com força destacável no filme de Van der Keuken, por se constituir em uma espécie de réquiem antecipado de uma morte que o filme registrará. A imagem coletada é de intenção denotativamente real, isenta de recursos mais complexos de montagem

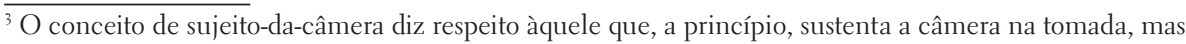
sua constituição deve ser pensada de forma abrangente. Ele não se limita à presença física do cinegrafista por detrás da objetiva, mas inclui toda a equipe de filmagem, somada à subjetividade do espectador que assiste ao olhar registrado pelo sujeito-da-câmera. (RAMOS, 2008). Ramos (2008) apresenta uma tipologia do sujeito-da-câmera cuja presença pode se caracterizar pela ocultação, ação, encenação ou afetação. Esse posicionamento é fundamental para a construção da tomada, tanto no aspecto formal, de posicionamento e ponto de vista, quanto para delimitar o campo ético do documentário e sua inserção social.

${ }^{4}$ Em Du litteraire au filmique (1989), Gaudreault versa sobre a narrativa fílmica, desenvolvendo o conceito de "mostração" em contraposição a "narração". Segundo o autor, o cinema combina essas duas instâncias temporalmente separadas. Num primeiro momento, há a captação da imagem, em que o cinema empresta do teatro a noção de mostrar seus personagens - reais ou ficcionais - agindo diante da câmera (GAUDREAULT, 1989), o que é nomeado pelo autor como a mostração. Essa é a primeira temporalidade, que foi a base do primeiro cinema, em que a câmera era utilizada para registrar planos-quadros ou planos autônomos (GAUDREAULT, 1989). Com o desenvolvimento da linguagem cinematográfica, as tomadas passaram a ser organizadas pela instância narrativa, caracterizada, para o autor, pela montagem. Esta acarreta em uma dupla temporalidade no cinema - a do mostrar, no momento de captação, e a do narrar, na justaposição dos planos. Para ele, o realizador combina essas duas funções de "mostrador-fílmico" e narrador-fílmico. Gaudreault também questiona se apenas a ficção seria considerada narrativa e, ainda que não forneça uma resposta categórica, salienta que os filmes teoricamente considerados não narrativos (documentários, filmes didáticos etc.) seguem os mesmos mecanismos semiológicos do chamado "grande cinema” (GAUDREAULT, 1989, p. 27), ou seja, também são regidos por essas duas instâncias.
} 
(incluindo alguns cortes abruptos), que em si transmite a ideia de veracidade, autenticidade e de intimidade. Isso é ainda mais enfatizado pela filmagem em $16 \mathrm{~mm}$, que remete à estética de um filme caseiro. Nesse sentido, o filme de Van der Keuken caracteriza-se como uma obra que pode ser compreendida em duas polaridades: a da filmografia de família, que foi estudada, com primazia, por Roger Odin; e, nas bases etnográficas contemporâneas, a da etnografia doméstica, de Michael Renov.

Para Odin, o filme de família opera na lógica da reconstrução de um passado mítico daquilo que foi vivido, ou seja, as imagens registradas recuperam um imaginário, ainda que baseadas no "real”, uma vez que se constrói, por meio delas, uma ficção familiar (ODIN, 1995). Nessa clave, o filme de Van der Keuken oscila entre vetores distintos. Há, por um lado, o anseio de registrar a irmã, na tentativa de captar seu papel no mundo. Joke era psicóloga especializada no tratamento de dependentes químicos, o que Van der Keuken procura ressaltar por meio do diálogo sobre a carreira e os pacientes. Ao mesmo tempo, há um processo mais abrangente de reflexão sobre a família e, concomitantemente, o desejo de reconstruir, por meio dos fragmentos da memória, o passado mítico do que foi vivido pelos envolvidos. Essa reconstrução apoia-se, além das falas de Joke e de Van der Keuken, em diversas fotografias exibidas ao longo do filme. Aos 16 minutos, o documentarista, que está fora do quadro filmando a irmã, afirma que sua motivação para realizar o filme era uma foto da irmã grávida aos 19 anos, em 1955, e propõe a recriação dessa fotografia. Joke, então, posa com braço encostado na testa, e Van der Keuken afirma que sua ideia é captar algo de eterno no rosto de Joke, o que ele intenta por meio de uma fotografia filmada da irmã doente. A recriação da fotografia de 1955 serve como gatilho para que o documentarista e sua irmã relembrem a infância conjunta, a casa de veraneio da família, a relação dos irmãos com os pais, o nascimento das sobrinhas. Além dessa marcante sequência, Van der Keuken encerra o documentário com uma exposição seca de fotografias de Joke, em ordem inversamente cronológica: da morte para uma foto dela recém-nascida. Percebe-se, assim, que ambos os vetores apontam para a tentativa de perpetuar e reiterar a imagem e a significação da irmã e, consequentemente, a da família.

$\mathrm{Na}$ outra polaridade, esse filme pode ser analisado com base no recorte da etnografia doméstica, proposta por Michael Renov (1999). A etnografia doméstica, segundo Renov, é o veículo para o autoexame (self-examination), o que significa que o documentarista se vale do recurso de focar-se em um ente familiar ou uma pessoa próxima com a qual ele conviva e tenha certa intimidade - em que ele, direta ou indiretamente, inscreve um tipo suplementar de autobiografia. Isso porque, segundo 
Renov (1999), a etnografia doméstica é mais do que uma simples variante do discurso autobiográfico. Ela seria uma forma de se atingir o autoconhecimento por meio do autoexame, com base na investigação da afeição e do ressentimento, uma vez que o outro não é o exótico, mas o familiar, o conhecido. Renov afirma que há um estranho tipo de reciprocidade que faz parte dessas outras subjetividades neste modo que o autor denomina para-etnográfico.

Ao falar da irmã, Van der Keuken trata de si e opera sua própria experiência, refletindo sobre sua trajetória e sua família, a partir dos efeitos da trajetória da irmã. Pode-se destacar o diálogo em que Van der Keuken e Joke discutem sobre como os dois eram vistos pelos pais na adolescência. Enquanto Joke era considerada a filha rebelde, o documentarista era o bom filho. Van der Keuken reflete também sobre as implicações que o comportamento e, em especial, a gravidez precoce da irmã tiveram em sua vida na época. Há uma participação ativa do sujeito-da-câmera dentro do documentário, uma vez que Van der Keuken faz também uma releitura de si mesmo por meio do contraste com a irmã.

Sobre essa questão, Renov recorre ao conceito de co(i)mplicação, na qual o registro do objeto, ou tema do filme (no caso, Joke), implica a documentação também do realizador, de forma que suas identidades, sujeito/objeto, confundem-se e complicam-se na imagem fílmica, uma vez que a proximidade de laços entre ambos é elemento central na construção de sentido do filme. Ao mesmo tempo em que o filme é possibilitado justamente pela ligação e a intimidade da relação familiar, o discurso preponderantemente subjetivo e intimista de Joke é viabilizado pelo seu vínculo de sangue com o documentarista, uma vez que este possibilita não somente a franqueza do discurso, mas, também, faz que o entrevistador e a entrevistada partilhem suas lembranças e subjetividades.

os filmes e fitas que eu denomino etnografia doméstica brincam na fronteira do dentro e fora (insideloutside) de forma única. Esse trabalho se dedica à documentação de familiares ou, menos literalmente, de pessoas com quem o realizador manteve relações diárias duradouras e obteve, assim, um nível de intimidade casual. Como as vidas dos artistas e sujeitos estão interlaçadas por meio de relações comunais ou de sangue, a documentação de um tende a implicar o outro de maneiras complicadas; de fato, consanguinidade e co(i)mplicação são as características definidoras das etnografias domésticas. Por co(i)mplicação eu quero dizer tanto complexidade como interpenetração da identidade de sujeitos/objetos. Levando a questão ainda mais longe, pode-se afirmar que a etnografia doméstica é um tipo suplementar de prática autobiográfica; 
funciona como um veículo de autoexaminação, um meio pelo qual se constrói autoconhecimento recorrendo ao outro familiar. (RENOV, 1999, p. 141, tradução nossa)

Por outro lado, o documentarista assume a posição de observador participante ao tentar detalhar o processo da perda pelo avanço da doença, notadamente apoiado nas diferentes temporalidades do discurso de sua irmã Joke, pontuando a reflexão de sua autoimagem, ao interagir com a irmã e realizar um filme. Assim, o que marca a etnografia doméstica é justamente a condição de interdependência entre o objeto do filme e quem o faz. Isso ocorre também porque o sujeito da etnografia doméstica, enquanto tal, existe apenas em função de sua relação constitutiva com o realizador (RENOV, 1999, p. 142).

Ressalta-se, ainda, a impossibilidade de constituir-se um olhar totalmente distanciado do objeto. Na condição de observador participante, o documentarista, na dicotomia insideloutside, não estará totalmente fora, porquanto compartilha com o objeto do filme traços comuns: de família, de imaginário e de memórias. No caso de Last words, observa-se que Van der Keuken acrescentará comentários ao discurso de Joke, sobre seus relatos e, ao mesmo tempo, comenta a respeito do comportamento e da persona dela, destacando o quanto as decisões e atos da irmã o influenciaram em suas atitudes e em sua relação com seus pais.

Como contraponto, tempos depois, o próprio Van der Keuken é acometido por um câncer terminal e realiza outro documentário expondo suas idas ao médico e seu diagnóstico pouco animador. Nesse filme, Férias prolongadas, Van der Keuken, em vez de fustigar a imagem da memória familiar, investe em registrar uma viagem para locais distantes da sua terra natal - Tibete, Brasil e África. Ao tratar de sua própria doença, ele não se detém em relatar sua condição em primeira pessoa, por meio de uma entrevista em close, como é feito com sua irmã. Para registrar suas próprias “últimas palavras”, Van der Keuken utiliza o plano ponto-de-vista, enfocando o mundo que o rodeia.

\section{A palavra e a imagem: fotografia, memória e luto}

A posição da câmera, ao longo do filme, é predominantemente estática. Ela privilegia o close de Joke, para, em certos momentos, intercalar esse close com algumas tomadas com traços mais poéticos, principalmente nos planos-detalhe evocativos de objetos e fotografias, além de pequenos travellings e panorâmicas que exibem a casa e o quarto do hospital. Em busca de referências, em outro momento, o 
documentarista justapõe o relato de Joke às imagens das filhas, Else e Barbra, e à fala da irmã mais velha, Frieda, que é mencionada como uma espécie de mãe dos dois. Os três entes familiares, em oposição a Joke, que está confinada em casa e no hospital, são filmados em seus locais de trabalho: a sede da sala de concertos da Concertgebouw de Amsterdã, uma loja de antiguidades e um ateliê de pintura.

No caso das filhas de Joke, percebe-se um grande constrangimento pela presença da câmera. Barbra e sua filha Laura, neta de Joke, são filmadas em seu ateliê de pintura em frente a uma tela. A câmera apenas as observa estáticas, em composição de filme familiar. Else, por sua vez, é filmada em um ensaio da orquestra. Ao contrário da irmã, Else chega a dar um depoimento afirmando que, apesar de suas viagens com a orquestra, ela conseguia manter contato frequente com a mãe pelo telefone e explica suas funções dentro da orquestra. Ainda que Else não se mantenha estática e em silêncio como Barbra, o enquadramento da tomada em plano-médio e sua posição em pé com o parapeito do camarote da sala de concerto ao fundo remetem a uma fotografia still. A sequência das irmãs inicia-se com elas em silêncio, sendo filmadas paradas, com a voz over de Joke falando delas e de suas carreiras. Dessa forma, como fez com Joke, ao recriar a fotografia da adolescência, as tomadas de suas filhas também se estruturam como fotografias filmadas, como se o sujeito-da-câmera estivesse realizando um álbum de família, o que é ainda mais enfatizado na sequência com Frieda, a irmã mais velha, falando sobre a doença de Joke.

Observa-se que a estrutura narrativa do filme é centrada na fala de Joke, marcada pela memória, pela condição emotiva e pela impregnação de fragilidade e de uma postura de despedida. Nesse sentido, a relação de Joke com as filhas é uma das tônicas do documentário, em função da importância e dificuldades que a gravidez significou em sua trajetória e como isso repercutiu na família. Por isso, é destacável que as poucas vezes em que Joke realmente se emociona são as em que ela fala sobre a reação das filhas ao saberem da volta do câncer da mãe, de quando percebeu que teria que usar o tempo que restava de vida para se despedir das pessoas e se desligar da vida e, por fim, no hospital, em vias de morrer, quando descreveu a morte como "um doce sonho". No mais, o discurso é bastante racional e procura manter-se objetivo (como, por exemplo, quando Joke explica como fez para se desligar das atividades profissionais ou quando faz uma revisão sobre a história de sua vida).

O documentário, então, aponta para um duplo caminho. Como um discurso fílmico, o filme de Van der Keuken está quase totalmente calcado na palavra, no relato subjetivo, individual, realizado na forma de entrevista. As imagens são os suportes e formas de registrar esse relato. A câmera permanece predominantemente estática, em 
um close da irmã, que fala frontalmente, respondendo às perguntas e intervenções de Van der Keuken ${ }^{5}$, cuja única presença é sua voz fora de campo (recurso de voz off, bastante comum em entrevistas que desejam priorizar a participação do entrevistado), nunca seu corpo.

Essa forma de construção das tomadas coincide com o que Renov classificou como vídeo confessional. Este, além do diálogo, traz a possibilidade de autoanálise, tanto do entrevistado quando do cineasta. A argumentação de Renov acerca do tema parte da noção religiosa de confissão indo em direção à questão psicanalítica para afirmar, citando Jean Rouch, que a câmera pode ser um instrumento de confissão, uma vez que esta possui dupla função: ela é uma janela que apresenta o pró-fílmico para um olhar ausente e, ao mesmo tempo, se organiza como uma estrutura refletiva que nos reintroduz para nós mesmos (RENOV, 2004).

Renov salienta que esse tipo de fazer cinematográfico é mais condizente com vídeos em primeira pessoa, utilizando espelhos ou tripés ou - como no caso de Last words - sem grandes equipes de filmagem, muitas vezes privilegiando o vídeo em detrimento do filme $e^{6}$. Isso porque a confissão, em geral, presume uma intimidade que a presença de operadores de câmera, som, luz e outros aparatos cinematográficos inibiria. Renov destaca que a presença virtual de um parceiro ou ouvinte - o outro imaginado que se concretiza pela tecnologia - torna-se um facilitador mais poderoso da emoção do que interlocutores ao vivo (RENOV, 2004). A câmera, como aparato e potencialidade, torna-se um facilitador da autoanálise, uma vez que é dada a oportunidade ao falante de revelar fatos escondidos, acontecimentos do passado ou sentimentos. Renov salienta que isso ocorre, sobretudo, nas produções em primeira pessoa, porque quem fala tem o domínio da câmera e, muitas vezes, está sozinho com ela.

Contudo, em Last words, as confissões de Joke são mediadas pelo irmão. Pode-se pensar que a câmera de Van der Keuken nesse filme flerta também com o plano ponto-de-vista. Isso porque a fala de Joke é dirigida a ele, enquanto ela fala olhando diretamente para a objetiva. Todavia, trata-se apenas de uma aproximação ou

\footnotetext{
${ }^{5}$ Há uma terceira pessoa que interfere na entrevista e faz perguntas a Joke, até o minuto 36 do documentário, em que ela está sendo filmada em sua casa. Trata-se da esposa e colaboradora de Van der Keuken, Noshka van der Lely. No hospital, Van der Keuken dialoga com outra pessoa (quando ele pede para fechar a porta, mas permite que essa pessoa fique no quarto), mas ela não intervém no diálogo nem é registrada.

${ }^{6}$ Apesar disso, Renov destaca que A crônica de um verão (1961), de Jean Rouch e Edgard Morin, além de ser um experimento monumental do cinema direto, pode ser visto como um marco no desenvolvimento de confissões para a câmera (RENOV, 2004).
} 
flerte, uma vez que não estão suficientemente presentes na decupagem os elementos caraterísticos que explicitariam para o espectador que se trata de um plano pontode-vista $^{7}$ do diretor, isto é, que evidenciariam que aquela é a experiência visual de Van der Keuken. Além disso, ainda que a conversa seja íntima e confessional, as falas não se destinam a circular apenas dentro da esfera familiar. Ao contrário, há uma clara intenção, tanto de Joke quanto de Joahan, de didaticamente situar e incluir o espectador, para que este possa compreender e acompanhar a trajetória familiar.

Retomando as reflexões de Renov, pode-se perceber como a presença da câmera somada a do irmão e da cunhada criam um espaço para a confissão e, junto com ela, a autoanálise e reflexão sobre a vida e a morte, e sobre a família. Além disso, a escolha do enquadramento nos leva a outras possibilidades interpretativas. Recorde-se, aliás, que a proposta do documentário surgiu inspirada por foto de Joke grávida aos 19 anos, foto essa que Van der Keuken propõe que seja recriada durante o documentário. Ao encenar sua recriação tardia, ele estabelece um contraste entre a jovem com a vida pela frente, aflita pela gravidez precoce, e a realidade da mulher à beira da morte, com um caminho percorrido, tendo superado os desafios, se tornado uma profissional respeitada e mãe amorosa. Nesse sentido, embora a narrativa do documentário privilegie a palavra, sobretudo na modalidade confessional, a importância da imagem-câmera (RAMOS, 2008) está na intenção de retrato que permeia todo o filme, conferindo-lhe o ethos de um álbum de família, no afã de registrar momentos íntimos e altamente subjetivos e documentar a memória familiar.

Essa escolha estilística do documentarista em fazer retratos filmados ao longo do filme, remetendo à fotografia still, nos leva a algumas ponderações sobre o cinema e a fotografia feitas por Raymond Bellour (1997), bem como permitem inquirir acerca da intenção do documentarista em buscar uma aproximação entre os dois meios artísticos. O autor de Entre-imagens salienta, a partir de Roland Barthes, a distinção entre o cinema e a fotografia e, também, os efeitos da fotografia no filme. Bellour afirma que enquanto o cinema aponta para o presente, em função do movimento, a fotografia, devido a sua imobilidade, indica o passado, ou seja, indica a ausência. A fotografia, então, possui uma dupla articulação: ao mesmo tempo em que expressa a passagem do tempo, ela resiste a ele, justamente porque

\footnotetext{
${ }^{7}$ O plano ponto-de-vista (poin-of-view shot) foi estudado de forma minuciosa por Edward Branigan em Point of view in the cinema (1984). Branigan disserta e elabora uma série de diagramas para explicar como esse plano é construído pela decupagem e quais os elementos necessários para que se possa atribuir determinado plano a um olhar específico, seja do personagem ou do diretor participativo. Os recursos que podem ser empregados são distintos, mas sempre visam simular para o espectador uma experiência dos personagens, incluindo a sua experiência visual (WALTON, 2005).
} 
o fixa de maneira estática, terminando por simbolizá-lo. Ao fazer retratos filmados, Van der Keuken registra o presente da tomada, mas deixa subentendido que já se trata, na realidade, de um passado, tendo em vista que a realização de seu filme está predicada na morte da irmã.

A postura reflexiva do sujeito-da-câmera, de que é exemplo o filme de Van der Keuken, está bastante em voga, desde a década de 1990, nos documentários de vanguarda, opondo-se ao modelo expositivo de documentários caracterizados pela forma multifacetária de asserções, geralmente associados com o chamado documentário cabo. Nas modalidades vanguardistas de documentários nas quais se insere Van der Keuken, o discurso subjetivo, muitas vezes em primeira pessoa, é uma das principais formas de expressão e de construção de um recorte autoral no documentário (RAMOS, 2008). Assim, a tradicional objetividade e a grande quantidade de asserções são substituídas por uma enunciação subjetiva e, muitas vezes, até poética.

Qual o interesse em trazer a público, em exibir para espectadores, essa etnografia doméstica que mergulha na memória de uma pequena família e no relato subjetivo de um de seus membros? A resposta para essa indagação pode ser encontrada na importância do discurso subjetivo para a construção da narrativa moderna, originada no romance moderno. O relato subjetivo é um procedimento narrativo apoiado no individualismo, que garante o sentido de "real", de verossímil e autêntico, uma vez que a experiência e a trajetória de um indivíduo constituem uma narrativa nova e única, que não se repete e que não se repetirá (WATT, 2010). Assim, a experiência do homem comum tornou-se o tema do discurso moderno, o que na contemporaneidade levou à micronarrativa, calcada no discurso subjetivo, muitas vezes autobiográfico e em primeira pessoa, abordando materiais que envolvem acontecimentos traumáticos, dramas vivenciais e, como nesse caso, o enfrentamento da morte, o processo de finitude e as questões relacionadas à perda de entes queridos.

No tocante à narrativa da morte, é esclarecedora a posição de Vivian Sobchack (2005), ao se referir à representação da morte no documentário. Para ela, o evento da morte excede a representação, uma vez que a morte e o morrer, no filme documentário, não podem tornar-se visíveis na tela com a precisão que se experimenta em sua totalidade. Dessa forma, a mortificação visível configura-se como um índice do morrer, que só pode ser representável por meio do contraste do corpo vivo e o corpo como cadáver. Isso porque a representação da morte como algo "real", com signos estruturados de modo a funcionar inicialmente, implica a violação de um 
tabu visual, que deve ser justificado por esbarrar na questão ética da representação da morte no documentário ${ }^{8}$ (Sobchack, 2005).

No caso de Last words, o documentarista evidencia esse contraste já na abertura do filme. Logo após o título do filme, há uma tela preta com inscrições em branco, com a mesma formatação das anteriores, em que se lê o nome de Joke, sua data de nascimento e morte, ao estilo de uma lápide da entrevistada. Além disso, nas primeiras tomadas, a imagem-câmera mostra duas cadeiras em um jardim, enquanto ouve-se a voz de Joke em off relatando seu quadro clínico e a piora do seu câncer. A sequência inicia-se com as duas cadeiras vazias e, por meio de uma pequena sequência de panorâmicas, a câmera filma as plantas do jardim até que um corte seco apresenta a imagem de Joke. Dessa forma, pode-se pensar que logo na primeira sequência o documentário apresenta sua temática de retratar a ausência da retratada, alguém a quem não temos mais acesso senão por meio de seu discurso no filme e suas fotografias.

Além disso, esse índice do morrer também pode ser encontrado na sequência final. Nas tomadas no hospital, a visível fragilidade física da irmã se destaca em oposição às entrevistas precedentes e indicia a morte iminente. Joke termina sua fala afirmando estar muito cansada. Um corte seco passa para um plano detalhe de álbum de fotografias, no qual a primeira é uma fotografia de Joke, na cama hospitalar, já falecida. Uma mão acaricia a foto, e tem início uma sequência de fotos da irmã ao longo de sua vida.

Sobchack ressalta, ainda, como a representação da morte natural diferentemente da morte súbita e abrupta, causada pela violência - caracteriza-se como um processo, uma transformação lenta e imperceptível do animado em inanimado.

\footnotetext{
${ }^{8}$ Sobchak (2005), em "Inscrevendo o espaço ético: dez proposições sobre a morte, representação e documentário”, inicia sua argumentação citando Philippe Ariès para refletir sobre a transformação da morte de um evento social e público para uma experiência privada e antissocial, que sai da esfera doméstica para tornar-se um evento técnico, hospitalar, cercado de médicos e enfermeiros e originada em causas "alheias" com nomes exóticos ou de difícil compreensão. Assim, a morte natural tornou-se no século XX menos "natural", participando cada vez menos da vida cotidiana. Por isso, a morte transforma-se em tabu para o discurso público, o que limitou drasticamente as condições para sua representação. O espaço e o discurso público foram tomados, então, pela morte violenta - sobretudo em função da escalada da violência nos tempos atuais - tornando a morte em nossa cultura uma experiência súbita, inconveniente e chocante. Com isso, a ficção cinematográfica passa a ser o espaço de representação da morte, sobretudo quando esta é súbita, violenta, atroz e descontínua (SOBCHACK, 2005). No documentário, evita-se a representação da morte "real", uma vez que os tabus sociais que cercam a morte "real" aproximam sua representação de uma intenção pornográfica. Por isso, enquanto nos filmes de ficção a morte é experimentada como algo representável e até excessivamente visível, sendo suavizada pela visão mediada da ficção, no documentário ela se configura como uma representação que confunde. A representação do morto, do cadáver, no documentário, atrai a compaixão do espectador ao se configurar como um objeto que é um índice de um sujeito que era (SOBCHACK, 2005).
} 
o contrário, a morte natural constrói suas próprias expectativas e as cumpre ao longo de uma durée percebida. Com respeito à sua representação visual, ela existe em equivalência temporal com o transcorrer no tempo presente do meio fílmico, estabelecendo pouco ou nenhum contraste entre movimento e ação congelada, entre a presença como um ser corporificado e um corpo meramente presente. (SOBCHACK, 2005, p. 139)

Será essa durée que Van der Keuken irá registrar, ainda que, como ressalta a autora, ela não seja tão eficiente como a representação da morte abrupta e violenta. O documentário pretende capturar a transformação de Joke, tomando a evidência de sua debilidade física final como um índice da morte concreta já anunciada desde o início do filme. Nesse sentido, o filme registra os últimos momentos desse estágio animado de Joke, evidenciando, por meio de seus relatos e fotografias, sua transformação em decorrência da doença que a levará à morte.

A temática do documentário e o uso que nele se faz de entrevistas, testemunhos e fotografias, além da tentativa de eternizar Joke por meio da sua imagem fílmica, possuem outro desdobramento: o de utilizar o cinema para concretizar o luto do documentarista. O filme torna-se um meio de despedida, auxiliando a lidar com a perda. Ao mesmo tempo, tem a função de preencher o vazio causado pela ausência da irmã falecida, ao homenageá-la e tentar preservar sua vida filmicamente. O documentário apresenta quase que uma simplicidade formal, com a repetição do uso de planos médios dos entrevistados, cortes secos, grande ênfase na fala, o que intensifica sua proposta. Essa aparente simplicidade da decupagem e da montagem, que coloca o discurso em foco, inicialmente nos leva a pensar em uma representação bastante racional e objetiva, talvez até fria. Porém, o documentário de Van der Keuken possui um tratamento sensível, sem dramaticidade ou sentimentalismo, carregado de sentimento e delicadeza no olhar. Ao evitar os lugares comuns na representação da morte, como funerais, parentes chorando ou trilha sonora dramática, Van der Keuken termina por concentrar e intensificar a sensação de perda e luto. Isso porque, nessa forma que privilegia uma manifestação supostamente mais contida dos sentimentos, talvez condizente com a sociedade holandesa, o filme desnuda Joke com bastante honestidade, expondo a fragilidade de sua situação ao enfrentar seus últimos dias de vida, sem nela perder o foco por conta da exploração artificiosa de emoções exacerbadas. Ao mesmo tempo, a ênfase em Joke tem como antítese sua ausência já anunciada desde o início do filme pelo título e a inscrição com as datas de nascimento e morte. A forte presença de Joke na tela resulta em uma aura constante de luto e de morte, enfatizada pelos planos detalhes de objetos de sua casa e de fotografias, uma 
vez que essa presença é tratada pelo cineasta como explicitamente evocativa, como a representação de alguém que já deixou a existência. A consciência da morte possui, então, dois momentos no filme. A proposta do documentário surge em decorrência do câncer terminal de Joke e a fala de todos tem como subtexto a consciência de que ela vai morrer. Para o espectador, contudo, essa consciência é dupla, porque a morte, que era iminente no momento de captação das imagens, já se tornou um fato.

Renov, ao tratar do luto no documentário ${ }^{9}$, afirma que filmes ou vídeos que têm a perda como tema se caracterizam, em geral, como uma resposta às dores ou tristezas privadas ou familiares. Apesar disso, esses filmes quase sempre terminam sensibilizando outros indivíduos que possuem algum traço em comum com a proposta original. Indo mais além, o autor salienta que essa identificação geralmente vai além do público inicial que compartilha algo com a temática ou com o documentarista. Segundo Renov, o filme opera como um agente de luto tanto para o artista como para uma comunidade que compartilha a experiência de perda. A tristeza causada pela morte e o luto enquanto gatilhos para a realização fílmica podem gerar identificação até de espectadores que se encontram em uma posição completamente distinta da temática do documentário (RENOV, 2004). No caso de Last words, independentemente da relação ou experiência prévia do espectador com a perda de um ente querido, a certeza da finitude humana leva a esse processo de identificação tanto com a retratada quanto com o realizador. A universalidade do luto e da certeza da morte torna esse retrato tão particular e íntimo em algo comum a todos. Como afirma Renov, a representação da morte no documentário pode constituir-se como uma atividade tanto pública quanto autobiográfica ou intrapsíquica (RENOV, 2004). Assim, Last words configura-se a partir de dicotomias entre vida e morte, presença e ausência, particular e público, individual e coletivo.

\footnotetext{
9 Em "Filling up the hole in the real: death and mourning in contemporary documentary film and video", publicado no livro The subject of documentary (2004), Micheal Renov faz um estudo sobre a representação da morte no documentário. O autor aborda alguns exemplos das décadas de 1980 e 1990 e dá destaque ao filme Shoah (1985), de Claude Lanzmann, afirmando que por meio da memorialização da perda esses filmes se configuram como um trabalho de luto, que trabalha uma ausência, seja de um indivíduo específico ou uma coletividade, como no caso das vítimas do holocausto. Citando Barthes, Renov ressalta a capacidade do cinema de ser um local de representação da morte na sociedade, por ser um meio que intenta preservar a vida. A imagem em movimento é o "algum lugar" no qual os mortos são recordados e, ao mesmo tempo, anulados. Esses filmes e vídeos se organizam como uma resposta ao vazio no real causado pela morte, vazio este que o filme tenta preencher como forma de lidar com o sofrimento do luto. Por isso, Renov destaca que tais filmes tendem a ser construídos pela combinação das palavras (via voiceover em primeira pessoa ou testemunhos baseados em entrevistas) com as imagens (relíquias do passado, evocações de memória) cujo significado varia dependendo da organização dada pela edição (RENOV, 2004) para concretizarem na tela esse luto em forma fílmica.
} 


\section{Subjetividade e identificação}

Representar a subjetividade de um indivíduo em um documentário é diferente de representar a subjetividade de um personagem em um filme de ficção. O filme de ficção permite a utilização de mecanismos de identificação na estrutura dramática que facilitam a representação fílmica da subjetividade. O documentário, por sua vez, valer-se-á de outros modos de representar e registrar a subjetividade, e não apenas aquela do documentarista, por meio da voz over, ou da decupagem que privilegia o plano subjetivo da câmera.

O uso do discurso subjetivo no documentário e no filme etnográfico é tema de estudo para David MacDougall (1995). Segundo ele, o valor desse tipo de discurso ou da voz subjetiva no documentário, etnográfico ou antropológico, é que este garante acesso à junção de quadros ou frames de referência da sociedade. Nesse sentido, o filme pode envolver a subjetividade do documentarista, dos subjects do filme, ou do espectador. O que MacDougall ressalta é que neste processo se tem como objetivo observar o comportamento social e representar a cultura como um processo contínuo de interpretação e reinvenção.

Dessa forma, o filme de Van der Keuken, além de refletir e registrar a trajetória da irmã e de si mesmo, também reflete e ilumina a sociedade holandesa, especificamente, e a sociedade contemporânea em sua totalidade. A ponderação pessoal de Joke sobre a vida, a doença e a morte opera como um reflexo das características, das preocupações e medos da sociedade contemporânea. Ao mesmo tempo, sua trajetória pessoal traz à tona importantes questões relacionadas à emancipação feminina no século XX. Na primeira entrevista, ainda em sua casa, Noshka van der Lely, esposa de Van der Keuken, afirma que Joke enfrentou muitas dificuldades, sobretudo para poder estudar. Joke, então, relembra sua gravidez aos 19 anos na década de 1950. Ela não afirma ter sido mãe solo, mas diz que engravidou de um rapaz que também era estudante e que "não era um tipo de homem com quem se poderia ter uma relação séria”. Ela justifica que manteve esse relacionamento como uma atitude de rebeldia frente aos valores de seus pais e conclui afirmando que "tardou a ser uma mulher independente e respeitar a si mesma". O documentarista faz questão de enfatizar que, apesar das dificuldades, Joke conseguiu se estabelecer como uma psicóloga respeitada. Logo nas primeiras sequências do filme, enquanto Joke fala de seus pacientes e dos desenvolvimentos do seu trabalho assim que ela teve conhecimento de seu câncer, a imagem-câmera sai do close de Joke para focar em uma mesa com flores e livros e faz 
um zoom in em um dos livros, destacando que Joke era a autora daquela obra sobre alcoolismo, sua especialidade de trabalho como psicóloga.

Nesse sentido, ainda que não de modo aberto e panfletário, Johan caracteriza Joke como uma mulher que precisou conquistar sua independência, ou seja, que representa sua geração em sua luta pela liberdade sexual, pela conquista no mundo do trabalho e oposição ao modelo da geração anterior, em que a figura da mulher se mantinha restrita ao lar e às funções de mãe e esposa. O discurso subjetivo de Joke passa metonimicamente a representar não somente sua experiência individual e única, mas tendências e traços comuns e dominantes da sociedade. Dessa forma, a voz subjetiva se torna um ponto de partida para a leitura e compreensão da complexidade e da estrutura do fenômeno social.

Hoje, pelo contrário, as experiências de atores sociais individuais são vistas cada vez mais como pontos de vista estratégicos em uma sociedade que, na dinâmica complexa dos seus compromissos, estrutura "leituras" específicas do fenômeno social. O retrato de experiências subjetivas tornase uma estratégia para relocar o entendimento antropológico dentro das riquezas textuais da sociedade. O objetivo não é simplesmente apresentar a "visão indígena", nem invadir voyeuristicamente a consciência de outros indivíduos, mas ver o comportamento social e, de fato, a cultura, como um processo contínuo de interpretação e reinvenção. (MACDOUGALL, 1995, p. 219, tradução nossa)

Assim, as forças sociais ou os quadros de referência na sociedade, como denomina MacDougall, que são contraditórios, ambíguos ou paradoxais, podem ser representados objetivamente; no entanto, é argumentável, segundo o autor, que eles só podem ser compreendidos por meio do experiencial. Percebe-se, então, que no cerne desse processo de interpretação e observação do comportamento social, por meio da situação experiencial, está a identificação subjetiva do espectador com o filme.

Uma estratégia que, segundo este autor, viabiliza a construção da identificação entre o espectador, o sujeito e o documentarista é o uso do testemunho como forma narrativa em primeira pessoa, uma vez que ele aborda a subjetividade por meio da autoexpressão dos próprios sujeitos dos filmes (MACDOUGALL, 1995, p. 227). A voz subjetiva de Joke provoca diferentes reações no espectador, com base em suas referências e em sua própria subjetividade. Mesmo com a intervenção do documentarista que entrevista e faz perguntas, e dessa forma tem a possibilidade de conduzir o discurso, para o espectador existe uma interpretação subjacente, que descreve leituras pessoais que excedem ou complementam o que está sendo mostrado. 
Em concomitância, o uso do testemunho - e mais especificamente da entrevista - possibilita a identificação do espectador com o sujeito do filme, uma vez que garante acesso à informação narrada e falada e, também, a outra forma de informação que não é falada, mas exposta por meio de gestos e expressões. No caso do relato de Joke, observa-se que ela se emociona, chora em alguns momentos, o que traz outras informações e significados a seu relato, ao mesmo tempo em que comove e sensibiliza o espectador, enquanto relato ou reinterpretação de uma experiência humana. O espectador acaba por construir uma relação de empatia e solidariedade com o sofrimento de Joke, ao mesmo tempo em que ocorre uma identificação pelo aspecto universal da situação: a certeza da morte para todos, bem como a perda de um ente querido. Nessa chave, encontra-se o vínculo e a identificação do espectador para com um filme de família à qual ele não pertence.

Nesse sentido, MacDougall ressalta que o uso da entrevista no filme etnográfico emergiu do jornalismo e se tornou um elemento-chave dos documentários, em especial após a década de 1960, por ser um dos principais recursos de se obter informações sobre o tema tratado. Ele salienta que o entrevistado descreve suas próprias experiências subjetivas de eventos passados, enquanto simultaneamente o espectador as interpreta, o que confere um selo de credibilidade ao discurso. Porém, o autor ressalta que estas podem não ser totalmente fiáveis, uma vez que representam uma perspectiva limitada e uma mistura desigual de autojustificação (MACDOUGALL, 1995).

O filme, ao refletir a dicotomia da opacidade e da transparência, se mostra enquanto obra cinematográfica e não tem intenção de falsear ou naturalizar a presença da câmera. Ainda que o relato de Joke esteja baseado em sua relação de intimidade com o documentarista, Van der Keuken expõe alguns traços do fazer fílmico nas sequências do filme. O documentarista não somente faz perguntas em off, como faz intervenções específicas, enunciando suas intenções de montagem ou de movimentação de câmera. Além da já mencionada fotografia que Van der Keuken recria, afirmando que irá incluir na montagem do filme a fotografia original de 1955, comparando-a com um longo superclose da irmã estática e em silêncio, ele também chega a enunciar sua movimentação, como quando diz: "Vou me aproximar com a câmera". Dessa forma, o documentarista desnaturaliza o discurso, ao deixar o espectador alerta e sempre consciente da presença da câmera, da técnica cinematográfica e do fato de que se trata de uma filmagem. 


\section{Considerações finais}

Ao assistir o documentário Last words, de Johan van der Keuken, o espectador se defronta com uma problemática a princípio bastante íntima, a doença e a morte da irmã, mas que, ao mesmo tempo, possui um forte aspecto universal, comovendo e promovendo a identificação com o espectador.

Esse dualismo percorre todo o filme. No estudo proposto, tentou-se abordar essa problemática com base nas posições sobre cinema de Roger Odin, quando se refletiu sobre a matriz do filme de família; na de Michael Renov, no tocante à etnografia doméstica, enquanto forma de autorreflexão e autoexaminação; e na de David MacDougall, quando se refletiu sobre a questão da subjetividade e suas formas de manifestação, por meio do testemunho e da entrevista.

Adicionalmente, por se tratar de uma matéria-prima caracteristicamente sensível a todos os indivíduos - a condição de morte -, refletiu-se sobre a concentração no discurso sobre a vida e a morte na forma narrativa desse filme e suas implicações na recepção do espectador. Além disso, buscou-se destacar o importante papel da fotografia na estrutura fílmica, em sua relação com a memória e o passado. Sobre isso, tentou-se evidenciar que o filme foi construído com uma câmera predominantemente estática e em que a decupagem se limita ao close, que coloca em evidência a irmã do documentarista revelando sua intimidade, seu sofrimento, suas lembranças e, finalmente, seu pertencimento ao passado.

A intenção documentarizante de Van der Keuken é explícita na ideia básica do documentário de revelar, gravar e preservar, fixar no celuloide a irmã para que ela não seja esquecida. Nesse sentido, o documentário opera como registro de uma voz subjetiva, de um relato individual de uma pessoa comum, com uma trajetória comum, que se justifica não somente em função do parentesco com o diretor, ainda que muito em função dele, mas também enquanto micronarrativa que evidencia características do comportamento social, ao se constituir como um relato único, pessoal e novo. Ainda que comum e quase que prosaico, o relato possibilita, justamente como decorrência dessa condição, a identificação e a sensibilização do espectador sobre o ritual da morte.

\section{Referências}

BRANIGAN, E. Point of view in the cinema: a theory of narration and subjectivity in classical film. Berlin: Mouton Publishers, 1984.

BELLOUR, R. Entre-imagens. Campinas: Papirus, 1997. 
GAUDREAULT, A. Du littéraire au filmique: systeme du récit. Paris Meridiens Klincksieck, 1989.

MACDOUGALL, D. “The subjective voice in ethnographic film”. In: DEVEREAUX, L.; HILLMAN, R. (Eds.). Fields of vision: essays in film studies, visual anthropology and photography. Berkeley: University of California Press, 1995, p. 217-255.

ODIN, R. (Org). Les films de famille. Paris: Librairie des Méridiens, 1995.

RAMOS, F. P. Mas afinal o que é mesmo documentário? São Paulo: Senac, 2008.

RENOV, M. "Domestic ethnography and the construction of the 'other' self". In: GAINES, J. M.; RENOV, M. (Eds.). Collecting visible evidence. Minneapolis: University of Minnesota Press, 1999, p. 140-155.

2004.

The subject of documentary. Minneapolis: University of Minnesota Press,

SOBCHACK. V. "Inscrevendo o espaço ético: dez proposições sobre a morte, representação e documentário”. In: RAMOS, F. P. Teoria contemporânea do cinema. São Paulo: Senac, 2005, p. 127-158.

WATT, I. A ascensão do romance. São Paulo: Companhia das Letras, 2010.

WALTON, K. L. "Sobre imagens e fotografias: respostas a algumas objeções”. In: RAMOS, F. P. Teoria contemporânea do cinema. São Paulo: Senac, 2005, p. 105-125.

submetido em: 20 mar. 2018 | aprovado em: 24 set. 2018 